\title{
CONTRIBUTORS
}

Andrew Barreto, MD MS

Associate Professor of Neurology

Stroke Division, Department

of Neurology

University of Texas Health Science Center at Houston

Houston, TX

Liliana Cohen, MD

Jersey City Medical Center

Jersey City, NJ

Michael G. Fara, MD

Department of Neurology

NYU Langone Health

New York, NY

Christopher Favilla, MD

Assistant Professor of Neurology

University of Pennsylvania

Philadelphia, PA

Rahul Garg, MD

Department of Radiology

Rutgers Robert Wood Johnson

Medical School

New Brunswick, NJ

Toby I. Gropen, MD, FAHA

James H. Halsey Jr., MD

Endowed Professor and Chief,
Division of Cerebrovascular

Disease

Department of Neurology

Director, Comprehensive

Neurovascular and Stroke Center

The University of Alabama at

Birmingham

Birmingham, AL

Hen Hallevi, MD

Director, Neurology Department

A (Stroke)

Tel-Aviv Sourasky Medical Center

Tel Aviv, Israel

Nneka Ifejika, MD, MPH,

FAAPMR, FAHA

Stroke Section Chief

Associate Professor of Physical

Medicine and Rehabilitation

Associate Professor of Neurology and Neurotherapeutics

University of Texas Southwestern

Dallas, Texas

Koto Ishida, MD

Medical Director of Stroke

Department of Neurology

NYU Langone Health

New York, NY 
Lester Y. Leung, MD, MSc

Director, Comprehensive Stroke Center

Director, Stroke and Young Adults Program

Tufts Medical Center

Boston, MA

Ava L. Liberman, MD

Assistant Professor of Neurology

Albert Einstein College of Medicine

Montefiore Medical CenterBronx, NY

Kira Long, MD

Tulane University Department of Surgery

Tulane Medical School

University of Chicago

Chicago, IL

Sheryl Martin-Schild, MD, PhD, FANA, FAHA

Stroke Medical Director for Louisiana Emergency Response Network (LERN)

Medical Director of Neurology \& Stroke-Touro Infirmary

Medical Director of NeurologyNew Orleans East Hospital

Co-Director of the Stroke

Program-Our Lady of the Lake President \& CEO—Dr. Brain, Inc. New Orleans, LA

James S. McKinney, MD

Medical Director of NHRMC Stroke Program

New Hanover Regional Medical Center

Wilmington, NC
Deviyani Mehta, MD

Assistant Professor of Neurology

Department of Neurology

Rutgers Robert Wood Johnson Medical School

New Brunswick, NJ

Steven R. Messé, MD

Associate Professor of Neurology

University of Pennsylvania

Philadelphia, PA

Michael T. Mullen, MD, MSCE

Assistant Professor

University of Pennsylvania

Department of Neurology

Philadelphia, PA

Vikas Patel, MD

Vascular Neurology Fellow

Rutgers New Jersey Medical

School

Parlin, NJ

Christopher Renner, MD

Vascular Neurology Fellow

University of Pennsylvania

Philadelphia, PA

Igor Rybinnik, MD

Assistant Professor of Neurology

Rutgers Robert Wood Johnson

Medical School

New Brunswick, NJ

Amardeep Saluja, MD, FHRS

Director, Clinical Cardiac

Electrophysiology Laboratory

Robert Wood Johnson University

Hospital

New Brunswick, NJ 
Albert D. Sam II, MD, MS, MMM, FACS

The Vascular Experts/Southern CT Vascular Center

Director, Middlesex Hospital Limb Preservation Program

Middletown, Connecticut

Rajbeer Singh Sangha, MD

Fellow of Neurocritical Care

Northwestern Memorial Hospital

Chicago, IL

Steven M. Schonfeld, MD

Clinical Professor of Radiology

Chief, Division of Neuroradiology

Robert Wood Johnson Medical School New Brunswick, NJ

Magdy Selim, MD, PhD

Professor of Neurology

Harvard Medical School

Chief, Division of Stroke \&

Cerebrovascular Disease

Department of Neurology

Beth Israel Deaconess Medical Center

Boston, MA

Christina Mijalski Sells, MD, MPH

Clinical Assistant Professor,

Neurology \& Neurological Sciences

Telestroke Program Medical Director

Stanford University Medical Center

Stanford Stroke Center

Palo Alto, CA

James E. Siegler, MD

Vascular Neurology Fellow

University of Pennsylvania

Philadelphia, PA

Joseph Tarsia, MD

Assistant Professor of Neurology
University of Queensland,Ochsner Clinical School

Department of Vascular Neurology, Ochsner Neuroscience Institute

New Orleans, LA

Monica Verduzco-Gutierrez, MD

Assistant Professor of Physical Medicine and Rehabilitation

Vice Chair of Compliance, Quality and Patient Safety

McGovern Medical School at UTHealth

Medical Director of Brain Injury and Stroke Programs

TIRR/Memorial Hermann

Houston, TX

Linda C. Wendell, MD

Assistant Professor, Division of Neurocritical Care

Departments of Neurology and Neurosurgery and Section of Medical Education

Vice Chair of Education of Neurology

Director-Clinical Neurosciences Clerkship (Neurology), Sub-Internship in Neurology, and Advanced Elective in Neurology

The Warren Alpert School of Medicine at Brown University Providence, RI

Ashlie White, MD

Department of Surgery

Tulane Medical School

New Orleans, LA

Frank Wilklow, MD

Interventional Cardiologist

Touro Infirmary

New Orleans, LA 



\section{Ischemic Stroke}


